\title{
Organic farming and cover crops as an alternative to mineral fertilizers to improve soil physical properties**
}

\author{
Diego Sánchez de Cima ${ }^{1 *}$, Anne Luik ${ }^{2}$, and Endla Reintam ${ }^{1}$ \\ ${ }^{1}$ Department of Soil Science and Agrochemistry, Estonian University of Life Sciences, Kreutzwaldi 1, 51014 Tartu, Estonia \\ ${ }^{2}$ Department of Plant Protection, Estonian University of Life Sciences, Kreutzwaldi 1, 51014 Tartu, Estonia
}

Received May 14, 2015; accepted September 23, 2015

\begin{abstract}
A b s t r a c t. For testing how cover crops and different fertilization managements affect the soil physical properties in a plough based tillage system, a five-year crop rotation experiment (field pea, white potato, common barley undersown with red clover, red clover, and winter wheat) was set. The rotation was managed under four different farming systems: two conventional: with and without mineral fertilizers and two organic, both with winter cover crops (later ploughed and used as green manure) and one where cattle manure was added yearly. The measurements conducted were penetration resistance, soil water content, porosity, water permeability, and organic carbon. Yearly variations were linked to the number of tillage operations, and a cumulative effect of soil organic carbon in the soil as a result of the different fertilization amendments, organic or mineral. All the systems showed similar tendencies along the three years of study and differences were only found between the control and the other systems. Mineral fertilizers enhanced the overall physical soil conditions due to the higher yield in the system. In the organic systems, cover crops and cattle manure did not have a significant effect on soil physical properties in comparison with the conventional ones, which were kept bare during the winter period. The extra organic matter boosted the positive effect of crop rotation, but the higher number of tillage operations in both organic systems counteracted this effect to a greater or lesser extent.

K e y w o r d s: bulk density, compaction, manure, penetration resistance, porosity
\end{abstract}

\section{INTRODUCTION}

In the last 20 years, agriculture cannot be understood without the use of mechanization and fertilizers. The increasing number of operations and the use of larger equipment, in addition to the continuous and intensive cropping

*Corresponding author e-mail: Diego.Cima@emu.ee

**The study was supported by Estonian Scientific Foundation grant 7622, ERA_NET CORE-ORGANIC II project TILMANORG and by target financing project SF0170057s09, 2009-2014. systems, have led to soil degradation as a common problem on most of the farms that till the soil (Liu et al., 2007). In Estonia, one-third of the arable land is affected by some kind of degradation such as erosion, compaction, soil acidification, and other phenomena that reduce the soil fertility and crop productivity (Astover et al., 2006). In 2008, research carried out by the Agricultural Research Centre in collaboration with the Estonian University of Life Sciences defined soil compaction as one of the biggest problems affecting the soil not only at the regional level (Reintam et al., 2009a), but also as a current issue in most of the Eastern European soils (European Commission, 2006).

Compaction is defined as a process of densification, in which porosity and permeability are affected. This reduces water drainage and air exchange between the soil and the atmosphere (Weisskopf et al., 2010), hampers the root penetration, and diminishes the nutrient uptake, finally affecting the crop yield (Reintam et al., 2009a; 2009b).

In the past, nitrogen fertilizer amendments were considered as a compensatory measure for the negative effects of soil compaction. These fertilizers indirectly influenced the soil organic matter content by increasing crop productivity and root density (Edgerton, 2009) and the amount of soil organic carbon (SOC) when the crop residues were incorporated later into the soil. However, this costly practice is not environmentally sustainable since it carries a severe risk of nitrate contamination of soil and water (Ju et al., 2006).

(C) 2015 Institute of Agrophysics, Polish Academy of Sciences 
This contributed to increased research on different sustainable soil management strategies. During the last decades, the decline in SOC in most of agricultural systems and the awareness towards the importance of global $\mathrm{C}$ budgets have boosted the interest in organic farming as an alternative agricultural practice to enhance crop production and maintain soil quality under increasing world population and climate change conditions (Lal, 2009; van Diepeningen et al., 2006).

Organic farming relies on the use of cover crops, rotations, and residue management as some of the key practices for enhancing the organic matter content in the soil and hence improving the soil quality (Olesen et al., 2007). Several studies have shown that continuous applications via manure significantly reduce the values of compaction indicators such as bulk density and penetration resistance (Chen et al., 2013), stimulate the microbial and fauna activity of the soil, and enhance soil aggregate structure (Treonis et al., 2010). The use of crop rotations favours a more efficient use of soil nutrients by plants. Crops with different root lengths and densities are able to mobilize and extract nutrients and water from deeper layers. However, these roots also create biopores in the soil profile and can be used, especially plants with vigorous roots, to prevent and potentially alleviate problems derived from compaction as well (Chen and Wail, 2011). Finally, maintaining vegetation on crop fields during the off-season through cover cropping has been shown as a good measure to improve overall soil condition. Traditionally used for preventing erosion and nitrogen losses (Sainju et al., 2003), some winter cover crop species, like those from the genus Brassica, are used to potentially alleviate soil compaction problems due to their root system morphology (Hamza and Anderson 2005).

However, the positive effects of these practices are not permanent and changes during the whole rotation (Głąb et al., 2013) linked to the local soil and weather conditions, the crop species, the fertilization rates, tillage practices etc. can occur (Głąb and Kulig, 2008).

Despite the number of studies focused on the effect of organic and conventional farming practices on the chemical and biological properties, there is still no comparative research on soil physical properties under organic and conventional farming management (Papadopoulos et al., 2013). Similarly, research on cover crops has been confined to their use as nitrogen-binding agents and their effect on succeeding crops (Sainju et al., 2003), while relatively few studies on the effect of winter cover crops on soil physical properties under northern climate conditions have been conducted (Talgre et al., 2011).

The aim of this research is to contribute to this field of study by comparing the effect on soil physical properties -focusing on dry bulk density, porosity, penetrability, water retention capacity, and water availability- of four different fertilization managements under the basis of organic and conventional farming in a plough based tillage system.
Although physical changes in soil are expected in a longterm period, it was hypothesized that organic systems, due to the higher content of organic matter (green and cattle manure) and the presence of cover crops during the winter period, would offer more favourable soil physical conditions (lower bulk density, higher plant water availability, etc.), than the conventional systems within 4 years (2012) after the rotation was started (in 2008), even in an intensively tilled soil.

\section{MATERIAL AND METHODS}

In a field experiment set up at the experimental station of the Estonian University of Life Sciences in Eerika, Tartu, Estonia $\left(58^{\circ} 22^{\prime} \mathrm{N}, 26^{\circ} 40^{\prime} \mathrm{E}\right)$, soil physical properties under different farming systems were compared during the years 2010-2012. On a soil described as an Albic Stagnic Luvisol in the World Reference Base for soil resources classification (IUSS Working Group WRB, 2006), five-year crop rotation: winter wheat (Triticum aestivum L.), field pea (Pisum sativum L.), white potato (Solanum tuberosum L.), common barley (Hordeum vulgare L.) undersown with red clover (Trifolium pratense L.), and red clover - was established in 2008 . The soil texture fractions were $56.5 \%$ sand, $34 \%$ silt, and $9.5 \%$ clay and the humus layer had a depth between 27 and $29 \mathrm{~cm}$.

The experimental design consisted of eighty plots of approximately $66 \mathrm{~m}^{2}$, divided into four groups (farming systems). Each system was divided into four subgroups (replications) of five plots, where every plot corresponded to a different crop. The farming systems are described as follows:

- conventional I: used as a control, consisted of 20 plots under conventional management without any incorporation of chemical fertilizers $\left(\mathrm{N}_{0} \mathrm{P}_{0} \mathrm{~K}_{0}\right)$ but with a yearly addition of different pesticides;

- conventional II: 20 plots under conventional management where different concentrations of complex mineral fertilizers were added depending on the culture (common barley received $\mathrm{N}_{120} \mathrm{P}_{25} \mathrm{~K}_{95}$, winter wheat and white potato received $\mathrm{N}_{150} \mathrm{P}_{25} \mathrm{~K}_{95}$, low-N-rate $\mathrm{N}_{20} \mathrm{P}_{25} \mathrm{~K}_{95}$ was used for field pea, as it is a leguminous crop, and red clover alone was not fertilized). In addition, these plots were treated with different pesticides as well;

- organic I: 20 plots under organic farming conditions with the same crop rotation but including winter oilseed-rape (Brassica napus ssp. oleifera var. biennis) after pea, rye (Secale cereale L.) after potato, and perennial ryegrass (Lolium perenne L.) after winter wheat, as winter cover crops. In these plots weeds were removed by harrowing and no chemical plant protection was used;

- organic II: 20 plots under the same conditions than the previous system (organic I), plus manual addition, in autumn 2009 and every spring since 2010, of $40 \mathrm{t} \mathrm{ha}^{-1}$ of composted cattle manure in those plots where potato 
was cultivated. On average, the composted cattle manure contained: total nitrogen $(\mathrm{N})-9.7 \mathrm{~g} \mathrm{~kg}^{-1}$, total phosphorus $(\mathrm{P})-4.6 \mathrm{~g} \mathrm{~kg}^{-1}$, total potassium $(\mathrm{K})-8.6 \mathrm{~g} \mathrm{~kg}^{-1}$, total carbon $\left(\mathrm{C}-138 \mathrm{~g} \mathrm{~kg}^{-1}\right.$, total calcium $(\mathrm{Ca})-11.7 \mathrm{~g} \mathrm{~kg}^{-1}$, total magnesium $(\mathrm{Mg})-3.4 \mathrm{~g} \mathrm{~kg}^{-1}$, and $44.8 \%$ of dry matter (DM).

Organic and conventional plots were separated with an 18-meter long section of mixed grasses. This prevented the organic plots from being contaminated with synthetic pesticides and mineral fertilizers from the conventional side. In the case of organic systems, a 10-meter long protective area prevented manure spreading over those plots were it should not be used.

Both conventional systems were treated twice per year with herbicides, two to three times with different insecticides; meanwhile, fungicides were applied three to four times.

From 2008 to 2010, after the harvesting of field pea, white potato, and winter wheat in the conventional plots in the early autumn, no more operations took place on the soil until the end of October when the plots were ploughed at $22 \mathrm{~cm}$ depth. The plots where common barley was undersown with red clover remained unaltered during the winter period. No ploughing was done in autumn in 2011. Later, since 2012, the soil ploughing was done in spring at the same time as in the organic plots. In the case of the organic systems, winter cover crops were sown after harvesting the main crops and ploughed at the same depth $(22 \mathrm{~cm})$ into the soil the next year at the end of April. In May, barley with red clover and pea were sown in all systems and, finally, red clover was ploughed in July. During the spring, the plots were cultivated several times at $10-12 \mathrm{~cm}$ depending on the culture and the year and harrowed at $1 \mathrm{~cm}$ depth to destroy the weeds. The plots where potato was planted were cultivated at $25 \mathrm{~cm}$, harrowed at $4-5 \mathrm{~cm}$ depth, and subsequently furrowed and hilled.

It is important to remark that 2010 and 2011 were the third and fourth year, respectively, of conversion to organic farming. Hence, by 2011, the organic farming systems had already been fully organic. For a better understanding, in the present paper the notation 'organic' is used for defining both organic systems independently of the year.
The weather conditions differed slightly between the three years of study. In 2010, the average temperature (T) was $5.73^{\circ} \mathrm{C}$ with temperatures below zero already in the second half of November. The total precipitation $(\mathrm{P})$ was $598.6 \mathrm{~mm}$, concentrated mainly during the summer period. On the other hand, 2011 was warmer $\left(\mathrm{T}=6.28^{\circ} \mathrm{C}\right)$ and drier, with total precipitation $\mathrm{P}=454.8 \mathrm{~mm}$. Finally, 2012 was characterized by high precipitation occurring in the first half of the year in comparison with the two previous years, with $\mathrm{P}=584.6$ (Table 1 ), and an average temperature of $5.35^{\circ} \mathrm{C}$.

The sampling and measurements were done in autumn after harvesting the main crops from the medium section of each plot in 2010 and 2011. In 2012, samples were taken in spring before ploughing the soil.

A cone penetrometer (Eijkelkamp Penetrologger with 60 degree $1 \mathrm{~cm}^{2}$ cones) was used for measuring the penetration resistance down to $50 \mathrm{~cm}$ depth. For the rest of the physical properties studied, steel cores $(54 \mathrm{~mm}$ internal diameter and $40 \mathrm{~mm}$ height, with wall thickness approximately $1.5 \mathrm{~mm}$ ) were used at 5 to $10 \mathrm{~cm}$ depth, taking four replications of undisturbed soil per plot; this makes a total of 320 samples per year. In addition, for every plot, approximately 250 grams of soil were placed into plastic tubs for further analysis and determination of plant available/not available water content. For the soil organic carbon (SOC) analysis, 8 replications per plot were randomly taken at the same time from 0 to $25 \mathrm{~cm}$ depth and later combined to make one average sample. Every sample was air dried and passed through a $2 \mathrm{~mm}$ sieve.

At the Department of Soil Sciences and Agrochemistry of the Estonian University of Life Sciences, the soil cores were weighted (at field-moist condition) and capillary wetted for $24 \mathrm{~h}$ on a plate until saturation. Total porosity (TP), air filled pores (AFP), and dry bulk density $\left(\mathrm{p}_{\mathrm{d}}\right)$ were determined by subjecting the cylinders to constant drainage over a sand bed to a water tension of $6 \mathrm{kPa}$ for 12 days and later drying in the oven at $105^{\circ} \mathrm{C}$ for $24 \mathrm{~h}$ (Angers and Larney, 2007). Water permeability (k) was measured using aHauben permeameter(Eijkelkamp, The Netherlands). For the calculation of the plant available (PAW) and not available water (PnAW), three air dried soil replications

T a b l e 1. Average quarter (three months) temperature $(\mathrm{T})$ and total precipitation $(\mathrm{P})$ values at the experimental site during the period 2010-2012

\begin{tabular}{|c|c|c|c|c|c|c|c|c|}
\hline \multirow{2}{*}{ Year } & \multicolumn{2}{|c|}{ January-March } & \multicolumn{2}{|c|}{ April-June } & \multicolumn{2}{|c|}{ July-September } & \multicolumn{2}{|c|}{ October-December } \\
\hline & $\mathrm{T}\left({ }^{\circ} \mathrm{C}\right)$ & $\mathrm{P}(\mathrm{mm})$ & $\mathrm{T}\left({ }^{\circ} \mathrm{C}\right)$ & $\mathrm{P}(\mathrm{mm})$ & $\mathrm{T}\left({ }^{\circ} \mathrm{C}\right)$ & $\mathrm{P}(\mathrm{mm})$ & $\mathrm{T}\left({ }^{\circ} \mathrm{C}\right)$ & $\mathrm{P}(\mathrm{mm})$ \\
\hline 2010 & -4.10 & 75.4 & 11.09 & 160.4 & 17.20 & 235.8 & -1.25 & 127.0 \\
\hline 2011 & -5.94 & 32.4 & 11.52 & 104.8 & 15.99 & 182.8 & 3.57 & 134.8 \\
\hline 2012 & -5.77 & 85.8 & 9.93 & 221.4 & 14.93 & 205.0 & 2.95 & 113.0 \\
\hline
\end{tabular}


T a b l e 2. Mean values of the soil physical parameters and organic carbon, in the three years of study at the top layer (5-10 $\mathrm{cm})$

\begin{tabular}{|c|c|c|c|c|c|}
\hline Parameter & Year & Conventional I & Conventional II & Organic I & Organic II \\
\hline \multirow{3}{*}{$\theta(\%)$} & 2010 & $16.79 \mathrm{Aa}$ & $16.03 \mathrm{Aab}$ & $15.26 \mathrm{Ab}$ & 16.11Aab \\
\hline & 2011 & $16.33 \mathrm{Aa}$ & $16.48 \mathrm{Aa}$ & $18.12 \mathrm{Bb}$ & $18.03 \mathrm{Bb}$ \\
\hline & 2012 & $19.75 \mathrm{Ba}$ & $19.13 \mathrm{Ba}$ & $18.84 \mathrm{Ba}$ & $19.41 \mathrm{Ba}$ \\
\hline \multirow{3}{*}{$\mathrm{p}_{\mathrm{d}}\left(\mathrm{Mg} \mathrm{m}^{-3}\right)$} & 2010 & $1.53 \mathrm{Aa}$ & $1.53 \mathrm{Aa}$ & $1.60 \mathrm{Ab}$ & $1.59 \mathrm{Ab}$ \\
\hline & 2011 & $1.54 \mathrm{Aa}$ & $1.46 \mathrm{Bb}$ & 1.49Bab & $1.44 \mathrm{Bb}$ \\
\hline & 2012 & $1.45 \mathrm{Bab}$ & $1.39 \mathrm{Cb}$ & $1.47 \mathrm{Ba}$ & $1.48 \mathrm{Ba}$ \\
\hline \multirow{3}{*}{ ТР (\%) } & 2010 & $41.34 \mathrm{Aa}$ & $41.20 \mathrm{Aa}$ & $38.69 \mathrm{Ab}$ & $39.24 \mathrm{Ab}$ \\
\hline & 2011 & $40.88 \mathrm{Aa}$ & $44.14 \mathrm{Bb}$ & $42.86 \mathrm{Bab}$ & $44.68 \mathrm{Bb}$ \\
\hline & 2012 & $44.53 \mathrm{Bab}$ & $46.52 \mathrm{Cb}$ & $43.53 \mathrm{Ba}$ & $43.21 \mathrm{Ba}$ \\
\hline \multirow{3}{*}{ AFP (\%) } & 2010 & $16.70 \mathrm{Aa}$ & 14.11Aab & $11.78 \mathrm{Ab}$ & $12.49 \mathrm{Ab}$ \\
\hline & 2011 & $12.58 \mathrm{Ba}$ & $15.36 \mathrm{Ab}$ & $13.10 \mathrm{Aa}$ & $15.52 \mathrm{Bb}$ \\
\hline & 2012 & $15.96 \mathrm{Aa}$ & $19.11 \mathrm{Bb}$ & $14.62 \mathrm{Aa}$ & $14.07 \mathrm{ABa}$ \\
\hline \multirow{3}{*}{ PAW (\%) } & 2010 & 18.16Aa & $21.36 \mathrm{Ab}$ & $20.05 \mathrm{Abc}$ & 19.73Aac \\
\hline & 2011 & $16.66 \mathrm{Aa}$ & $20.83 \mathrm{Ab}$ & $15.81 \mathrm{Ba}$ & $16.48 \mathrm{Ba}$ \\
\hline & 2012 & $22.01 \mathrm{Ba}$ & $22.82 \mathrm{Ba}$ & $22.03 \mathrm{Ca}$ & $21.42 \mathrm{Ca}$ \\
\hline \multirow{3}{*}{ PnAW (\%) } & 2010 & $6.48 \mathrm{Aa}$ & $5.73 \mathrm{Ab}$ & 6.86Aac & 7.02Ac \\
\hline & 2011 & $11.63 \mathrm{Ba}$ & 7.93Ac & $13.95 \mathrm{Bb}$ & $12.75 \mathrm{Bab}$ \\
\hline & 2012 & $6.63 \mathrm{Aa}$ & $4.59 \mathrm{Bb}$ & $6.90 \mathrm{Aac}$ & 7.71Ac \\
\hline \multirow{3}{*}{$\mathrm{k}\left(\mathrm{cm} \mathrm{d}^{-1}\right)$} & 2010 & 87.74Aa & $96.50 \mathrm{Aa}$ & $19.88 \mathrm{Ab}$ & $26.72 \mathrm{Ab}$ \\
\hline & 2011 & $46.79 \mathrm{Ba}$ & $81.81 \mathrm{Ab}$ & $48.20 \mathrm{Ba}$ & $68.82 \mathrm{Ba}$ \\
\hline & 2012 & $103.8 \mathrm{Aa}$ & $82.32 \mathrm{Aa}$ & $94.68 \mathrm{Ca}$ & $91.32 \mathrm{Ca}$ \\
\hline \multirow{3}{*}{ SOC (\%) } & 2010 & $1.21 \mathrm{Aa}$ & $1.33 \mathrm{Ab}$ & $1.46 \mathrm{Ac}$ & $1.44 \mathrm{Ac}$ \\
\hline & 2011 & $1.10 \mathrm{Ba}$ & $1.32 \mathrm{Ab}$ & $1.35 \mathrm{Ab}$ & $1.37 \mathrm{Ab}$ \\
\hline & 2012 & $1.33 \mathrm{Ca}$ & $1.40 \mathrm{Ba}$ & $1.58 \mathrm{Bb}$ & $1.57 \mathrm{Bb}$ \\
\hline
\end{tabular}

$\theta$ - soil water content, $\mathrm{p}_{\mathrm{d}}$ - dry bulk density, TP - total porosity, AFP - air filled pores, PAW - plant available water, PnAW - plant not available water, $\mathrm{k}$ - soil water permeability, SOC - soil organic carbon content. Mean values followed by a different capital letter within each column indicates significant yearly differences $(t$-test, $\mathrm{p}<0.05)$ within the same system. Mean values followed by a different small letter within each row indicate significant difference (linear mixed model, $\mathrm{p}<0.05$ ) among the systems within the same year. 
from the tubs were placed in small steel cylinders $(1.5 \mathrm{~cm}$ diameter, $0.5 \mathrm{~cm}$ height, and $0.1 \mathrm{~cm}$ thick) and placed into pressure vessels at $1500 \mathrm{kPa}$ during 30 days, weighted, dried at $105^{\circ} \mathrm{C}$, and weighted again. Finally, soil organic carbon (SOC) was determined by the Tiurin method (Vorobyova, 1998).

To test the effect of the four fertilization systems on the soil penetration resistance at three depths, one-way analysis of variance was applied, followed by the least significant difference (LSD) test at the $95 \%$ level of confidence. The system effect on the different soil parameters was tested according to a general linear mixed model in R-Studio (R Core Team, 2012), considering also the effect of crop and repeated measurements made on the same plot, where $\mathrm{p}<0.05$ was considered as statistically significant. For testing the significant differences among the three years of study, the $t$-test was used.

\section{RESULTS AND DISCUSSION}

Even though bigger changes in physical soil properties may be expected in a longer term, within four years after the crop rotation started (in 2008), significant differences $(p<0.05)$ were already found among the systems.

Making an overall comparison of the soil physical properties in 2010 and 2012, despite the continuous tillage operations carried out in the systems, a general improvement in terms of soil porosity, water availability, permeability, and organic carbon content in the plough layer can be observed in all the systems (Table 2). Without taking into account other factors affecting soil structure analyzed later, this can be associated with a positive crop rotation effect (higher organic matter content and crop roots effect). Similarly to other studies (Carter et al., 2003; Hao et al., 2002), crop rotation showed a cumulative positive effect (Hao et al., 2002) on soil structural stability (higher porosity) and prevented soil organic carbon losses in the systems (Table 2).

The variability in the results along the years was also connected with the soil conditions at the time of sampling. In 2010 and 2011, soil samples were taken during the autumn period. By that time, the plots had been cultivated during the spring and main crops had already been harvested. On the other hand, in 2012, soil sampling took place in spring. Winter cover crops were present in the organic systems, in the conventional system only common barley undersown with red clover remained in the soil, while the other plots were just covered by plant residues (without tillage). Therefore, in 2010 and 2011, a notable tillage effect on the soil physical condition was expected as result of the operations previously carried out during the growing period. In turn, in 2012, the soil was kept unaltered until the sampling time and was only affected by the freezing and thawing cycles during the winter period and the organic systems benefited from the presence of the cover crops.
On the other hand, climate conditions during the whole year play an important role with regard to certain soil physical conditions. The weather conditions in 2011 were relatively drier in comparison with the other two years. In general, plant roots under moderate water stress conditions tend to increase the fine root length per unit soil volume, even in deeper soil layers (Chaves et al., 2002). Plant roots extend easily through macropores or regions of weakness in the soil, compacting the surrounding soil particles and decreasing the pore size. This is connected with the increase in PnAW (Table 2), which corresponds to the portion of water stored in the micropores. Reintam (2006) showed that under non-compacted soil conditions, root densities were lower in those plots where mineral fertilizers were added, since nutrients are found more accesible for plants. This can explain why despite the general increase in PnAW in 2011 , the porosity fraction remained basically unvariable in the Conventional II system. Lower root density resulted in lower compaction and hence the different porosity fractions remained the same.

The yearly variability as well as the differences among the systems can be the result of a cumulative fertilizer and SOC effect. On the one hand, the lack of any fertilization, mineral or organic, and/or cover crops, negatively affected the control system (Table 2). In addition, the relative low crop yield recorded in the system during the period from 2009 to 2011 (Tein et al., 2014) poorly contributed to maintenance of the SOC pool in the soil. Other shortterm experiments similarly showed a quick decline in soil organic carbon after a few years without any extra organic matter amendments (Liu et al., 2007).

On the other hand, the systems where fertilizers were applied showed an improvement in some of the soil physical parameters studied. Among the porosity fractions, AFP exhibited a positive response to the addition of mineral fertilizers (Table 2). The direct impact on soil physical properties derived from NPK fertilizers is hard to demonstrate (Głąb, 2014); however, previous studies have reported a positive response of SOC to the addition of chemical fertilizers in combination with crop rotation (Liu et al., 2007), mostly connected with higher crop yields. In the conventional II system during the period 2009-2011, Tein et al. (2014) found 45 to $55 \%$ higher potato yields than in the same plots under organic management, and on average, conventional systems exhibited a $80 \%$ higher yield than the organic ones. This corresponds to a bigger amount of crop residues incorporated into the soil, which in turn suggests a SOC source in the system that remains unaltered for a longer period due to the lower number of tillage operations carried out in the conventional systems.

In the organic systems, cover crops alone or with cattle manure had a significant effect on water permeability $(\mathrm{k})$ connected with the significant increase in SOC (Table 2). The average SOC gains (2010-2012) from winter cover crops in these systems were by $0.24-0.25$ and $0.17-0.18 \%$ 
higher in than the conventional I and conventional II system, respectively (Table 2). This suggests that the possible SOC stock losses from tillage, water erosion, and mineralization were lower than the SOC sequestered and maintained from the cover crops. Organic matter represents a food supply for earthworms and provides better living condition for the microfauna (Scullion et al., 2007). Organic I contained twice and organic II 2.6 times more earthworms, compared to the control system (unpublished data). Earthworms contribute to an increase in the number of medium and larger pores and hence an increase in water permeability.

However, the positive effect of cover crops and manure was counteracted by the higher number of tillage operations carried out in the organic systems. Tillage operations accelerated the mineralization of SOC, exposing aggregate protected $\mathrm{C}$ to microbial attack and soil particles to the effect of drying/rewetting and freezing/thawing cycles. In the same way, the conventional I system, compared with the rest of the systems, was more sensible to the effect of tillage operations due to the low organic matter in the system.

In the same way as the physical parameters previously discussed, all the systems showed similar decreasing tendencies with time in terms of penetration resistance (Fig. 1) as the balanced bulk density decreased and porosity increased (Table 2). At the ploughing depth $(22 \mathrm{~cm})$, the average values in 2010 ranged between 2.54 and 3.09 MPa for the Conventional I and Organic I systems, respectively (lowest and highest values); in 2012, these values ranged between 1.92 and $2.14 \mathrm{MPa}$ for the same systems. This might correspond to the crop rotation and SOC effect already explained and to differences in the soil water content at the time of sampling (Table 2) since these factors are directly correlated with the penetration resistance (Hamza and Anderson, 2005). It is important to note that even though the rest of the data collected derive from the analysis of the soil top layer $(5-10 \mathrm{~cm})$, looking at the penetration resistance diagrams, no big differences among the systems are expected at the ploughing depth (Fig. 1).

Despite the small number of tillage operations and the moderate weight of the tractor used $(5 \mathrm{t})$, the discontinuity in penetrability with depth under the ploughing layer (25$30 \mathrm{~cm}$ depth) observed in 2011 may explain the evidence of a possible plough pan. At this depth, around $8 \mathrm{~cm}$ below the tillage depth, penetration resistance normally reaches higher average values (Tsimba et al., 1999). However, the relatively low clay content (under 10\%), the small number of operations, and the natural processes of freezing/thawing and wetting/drying, do not make the soil very prone to structural problems due to soil compaction (Reintam, 2006). In fact, this soil hardening was a transient phenomenon and was not shown in 2012 (Fig. 1).

In the existing literature about penetration resistance, several authors including Whalley et al. (2012) concluded that, in general, penetrometer values greater than $2 \mathrm{MPa}$ can significantly affect the correct crop development and
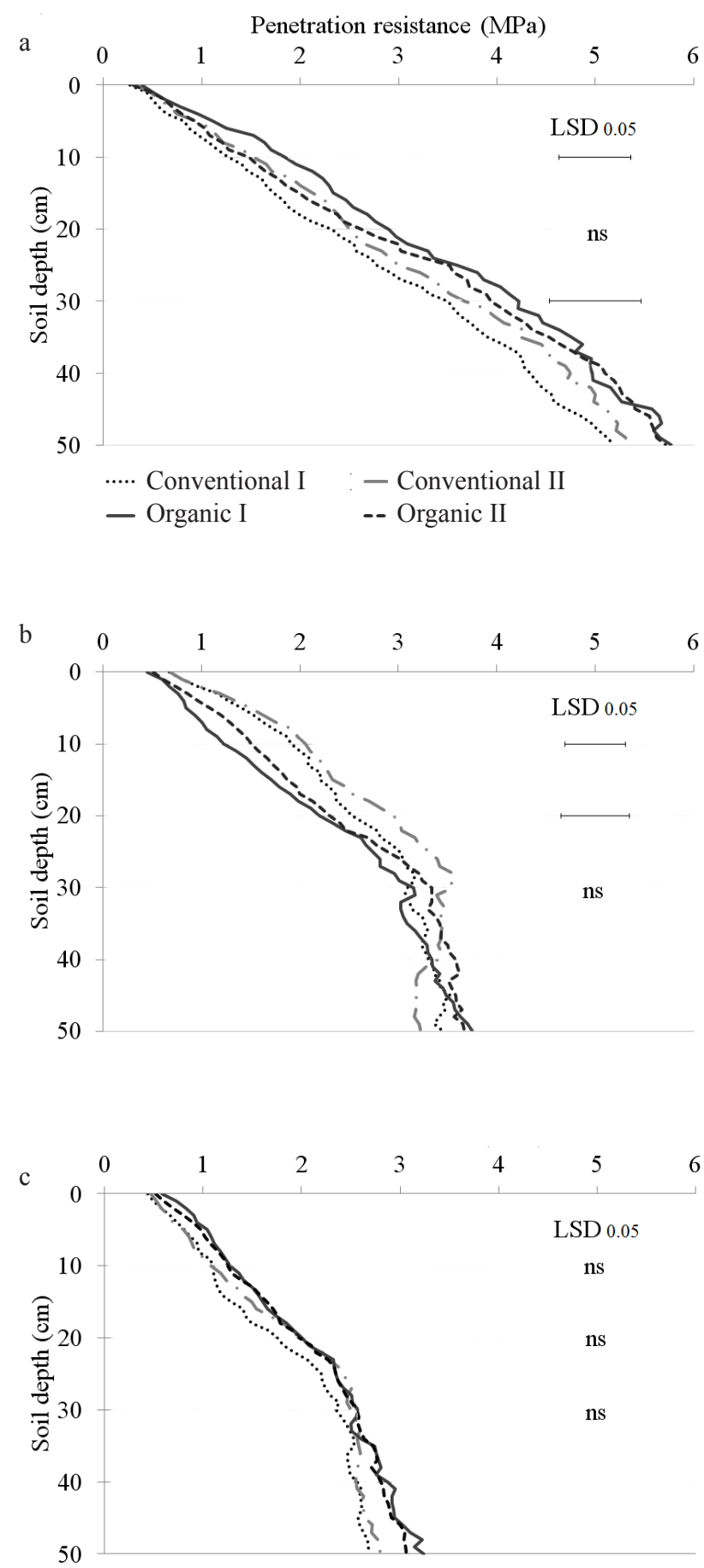

Fig. 1. Average penetration resistance $(\mathrm{MPa})$ with depth measured in the four systems in: $a-2010, b-2011$ and $c-2012$ year. $\mathrm{LSD}_{0.05}$ - least significant differences at significance $\mathrm{p}<0.05$, ns - not significant differences among treatments. Different capital letter indicates significant yearly $(2010,2011,2012)$ differences $(t$-test, $\mathrm{p}<0.05)$ within the same system (conventional I, conventional II, organic I, organic II) at the three studied depths: $10 \mathrm{~cm}$ (A,B,A; A,B,C; A,B,B; A,A,A), $20 \mathrm{~cm}$ (A,A,B; A,B,C; $\mathrm{A}, \mathrm{B}, \mathrm{B} ; \mathrm{A}, \mathrm{AB}, \mathrm{B}), 30 \mathrm{~cm}$ (A,A,B; A,A,B, A,B,C; A,B,C). 
the yield. These values were reached in 2010 and 2011 at $10-15 \mathrm{~cm}$ depth in some of the systems (Fig. 1). However, in the same field experiment, Tein et al. (2014) studied the crop yield response to four fertilization levels. The differences in yield found among the systems seem to be connected with the presence/absence of mineral fertilizers and not with problems derived from compaction.

The results derived from the present experiment do not confirm so far the initial hypothesis. Despite the higher amount of SOC, neither organic plot exhibited more favourable physical properties than in the conventional fertilized systems in the ploughing layer. However, many studies have presented a significant effect of cattle manure enhancing soil particle aggregation, reducing bulk density, and increasing water holding capacity (Hati and Bandyoopadhay, 2011) and hence bigger differences might be expected in a longer term.

\section{CONCLUSIONS}

1. Crop rotation and fertilization were the main factors affecting soil physical properties and soil organic carbon. Within 4 years after the crop rotation started, all the systems showed a general improvement in their soil physical condition in the plough layer: lower bulk density, higher plant available water and water permeability, and soil organic carbon), which is connected with a positive crop rotation effect.

2. The presence of winter cover crops, the return of the crop residues, and the application of cattle manure contributed to an increase in soil organic carbon and water permeability. However, in a short term, this effect was not statistically significant probably because the higher number of tillage operations counteracted this effect.

3. The lack of any fertilization treatment in the control system resulted in higher bulk density, lower percentage of air filled pores, plant available water and water permeability, and soil organic carbon compared with the other systems.

4. Mineral fertilizers boosted the positive effect of crop rotation to a greater degree than any of the organic managements proposed.

5. Taking into account that 2011 was the first year when organic systems could be considered fully organic and not all the plots had received cattle manure, bigger differences are expected in a long term linked to the disparity in the amount of organic matter among the systems.

\section{REFERENCES}

Angers D.A. and Larney F.J., 2007. Section VI: Soil physical analysis. In: Soil Sampling and Methods of Analysis (Eds M.R. Carter, E.G. Gregorich). Taylor and Francis. Canadian Soc. Soil Sci., 751-752.
Astover A., Roostalu H., Lauringson E., Lemetti I., Selge A., Talgre L., Vasiliev N., Mõtte M., Tõrra T., and Priit P., 2006. Changes in agricultural land use and in plan nutrient balances of arable soils in Estonia. Arch. Agron. Soil Sci., 52, 223-231.

Carter M.R., Kunelius H.T., Sanderson J.B., Kimpinski J., Platt H.W., and Bolinder M.A., 2003. Productivity parameters and soil health dynamics under long-term 2-year potato rotation in Atlantic Canada. Soil Till. Res., 72, 153-168.

Chaves M.M., Pereira J.S., Maroco J., Rodrigues M.L., Ricardo C.P.P., Osório M.L., Carvalho I., Faria T., and Pinheiro C., 2002. How plants cope with water stress in the field. Photosyntesis and growth. Ann. Bot., 89, 907-916.

Chen G. and Wail R.R., 2011. Root growth and yield of maize as affected by soil compaction and cover crops. Soil Till. Res., 117, 17-27.

Chen G., Wail R.R., and Hill L.R., 2013. Effects of compaction and cover crops on soil least limiting water range and air permeability. Soil Till. Res., 136, 61-69.

Edgerton M.D., 2009. Increasing crop productivity to meet global needs for feed, food, and fuel. Plant Physiol., 149, 7-13.

European Commission (EC), 2006. Thematic Strategy for Soil Protection. Communication from the Commission to the Council, the European Parliament, the European Economic and Social Committee and the Committee of the Regions. COM (2006) 231. Brussels, Belgium.

Gląb T., 2014. Effect of soil compaction and $\mathrm{N}$ fertilization on soil pore characteristics and physical quality of sandy loam soil under red clover/grass sward. Soil Till. Res., 144, 8-19.

Głąb T. and Kulig B., 2008. Effect of mulch and tillage system on soil porosity under wheat (Triticum aestivum). Soil Till. Res., 99, 169-178.

Głąb T., Ścigalska B., and Labuz B., 2013. Effect of crop rotations with triticale $(\times$ Triticosecale Wittm.) on soil pore characteristics. Geoderma, 202-203, 1-7.

Hamza M.A. and Anderson W.K., 2005. Soil compaction in cropping systems: a review of the nature, causes, and possible solutions. Soil Till. Res., 82, 121-145.

Hao Y., Lal R., Owens L.B., Lzaurralde R.C., Post W.M., and Hothem D.L., 2002. Effect of cropland management and slope position on soil organic carbon pool at the North Appalachian Experimental Watersheds. Soil Till. Res., 68, 133-142.

Hati K. and Bandyoopadhay K., 2011. Fertilizers (mineral, organic) effect on soil physical properties. In: Encyclopedia of Agrophysics (Eds J. Gliński, J. Horabik, J. Lipiec). Springer Press, Dordrecht-Heidelberg-London-New York.

IUSS Working Group WRB, 2006. World reference base for soil resources 2006. World Soil Resources Reports No. 103. FAO, Rome.

Ju X.T., Kou C.L., Zhang F.S., and Christie P., 2006. Nitrogen balance and groundwater nitrate contamination: Comparison among three intensive cropping systems on the North China Plain. Environ. Pollut., 143, 117-125.

Lal R., 2009. Soil and food sufficiency: A review. Agron Sutain. Dev., 29, 113-133. 
Liu B., Tu C., Hu S., Gumpertz M., and Ristaino J.B., 2007. Effect of organic, sustainable and conventional management strategies in grower fields on soil physical, chemical, and biological factors and the incidence of Southern blight. Appl. Soil Ecol., 37, 202-214.

Olesen J.E., Hansen E.M., Askegaard M., and Rasmussen I.A., 2007. The value of catch crops and organic manures for spring barley in organic arable farming. Field Crops Res., 100, 168-178.

Papadopoulos A., Bird N.R.A., Whitmore A.P., and Mooney S.J., 2013. Does organic management lead to enhanced soil physical quality? Geoderma, 213, 435-443.

R Core Team, 2012. R: a language and environment for statistical computing. R Foundation for Statistical Computing. Vienna, Austria $<$ http://www.R-project.org/ $>$.

Reintam E., 2006. Changes in soil properties, spring barley (Hordeum vulgare L.) and weed nutrition and community due to soil compaction and fertilization on sandy loam Stagnic Luvisol. A dissertation for applying for the degree of Doctor of Philososphy in soil sciences. Estonian University of Life Sciences.

Reintam E., Puust J., and Kuht J., 2009a. Soil compaction and nutrient uptake in an agroecosystem, Estonia - Land Degradation and Rehabilitation (Eds A. Faz Cano, A.R. Mermut, J.M. Arocena, R. Ortiz Silla). Reiskirchen, Catena Press, GMBH, 53-62.

Reintam E., Trükmann K., Kuht J., Nugis E., Edesi L., Astover A., Noormets M., Kauer K., Krebstein K., and Rannik K., 2009b. Soil compaction effects on soil bulk density and penetration resistance and growth of spring barley (Hordeum vulgare L.). Acta Agric. Scand., B, 59, 265-272.
Sainju U.M., Whitehead W.F., and Singh B.P., 2003. Cover crops and nitrogen fertilization effects on soil aggregation and carbon and nitrogen pools. Can. J. Soil. Sci., 83, 155-165.

Talgre L., Lauringson E., Makke A., and Lauk R., 2011. Biomass production and nitrogen binding of catch crop. Agriculture, 98, 251-258.

Tein B., Kauer K., Eremeev V., Luik A., Selge A., and Loit E., 2014. Farming systems affect potato (Solanum tuberosum L.) tuber and soil quality. Field Crops Res., 156, 1-11.

Treonis A.M., Austin E.E., Buyer J.S., Maul J.E., Spicer L., and Zasada I.A., 2010. Effects of organic amendment and tillage on soil microorganisms and microfauna. Appl. Soil Ecol., 46, 103-110.

Tsimba R. Hussain A., and Ndlovu R., 1999. Relationship between depth of tillage and soil physical characteristics of sites farmed by smallholders in Mutako and Chinyika in Zimbabwe. Research Book of the Animal Traction Network our Eastern and Southern Africa (ATNESA). Harare, Zimbabwe.

van Diepeningen A. D., de Vos O. J., Korthals G. W., and van Bruggen A. H. C., 2006. Effects of organic versus conventional management on chemical and biological parameters in agricultural soils. Appl. Soil Ecol., 31, 120-135.

Vorobyova L.A. 1998. Chemical analysis of soils. Moscow University Press, Moscow, Russia.

Weisskopf P., Reiser R., Rek J., and Oberholzer H.-R., 2010. Effect of different compaction impacts and varying subsequent management practices on soil structure, air regime and microbiological parameters. Soil Till. Res., 111, 65-74.

Whalley W.R., To J., Kay B.D., and Whitmore A.P., 2007. Prediction of the penetrometers resistance of soils with models with few parameters. Geoderma, 137, 370-377. 